\title{
A fala de telejornalistas de duas capitais nordestinas
}

Gabriela Silveira Sóstenes ${ }^{1}$

Aldir Santos de Paula ${ }^{2}$

\section{Resumo}

Esta pesquisa teve como objetivo descrever as características segmentais da fala de telejornalistas de duas cidades (Recife e Maceió), em emissão espontânea e profissional. Este estudo foi realizado nas emissoras da Central Globo de Jornalismo e Esporte do Recife, e na afiliada da Rede Globo de Maceió. Para avaliar a emissão espontânea, foi utilizada conversa espontânea sobre experiências pessoais. Para a emissão profissional, foi solicitado que os repórteres lessem um texto padrão, simulando o estilo de narração do telejornalismo. Os telejornalistas avaliados modificaram suas pronúncias de origem na fala profissional, já em emissão espontânea, houve um "despoliciamento" em manter o padrão telejornalístico.

Palavras-chave: Variação linguística. Sotaque. Telejornalismo

${ }^{1}$ Universidade de Ciências da Saúde de Alagoas.

2 Universidade Federal de Alagoas. 


\section{Introdução}

A língua é um meio de interação entre os indivíduos e, por meio dela, os mesmos são identificados e diferenciados em suas respectivas comunidades e inseridos em diferentes grupos e contextos de comunicação. Desta forma, por conta destes e de outros fatores, o indivíduo ainda pode ser rotulado de acordo com sua nacionalidade e naturalidade, sua condição econômica ou social, sexo, idade, escolaridade e profissão.

Estudar a língua usada por uma comunidade, correlacionando os aspectos linguísticos e sociais, é uma das tarefas da Teoria da Variação Linguística. Ao estudar a língua no seio de uma comunidade de fala, depara-se com a realidade da variação linguística, pois os membros de uma dada comunidade são falantes de sexo e idades diferentes, pertencentes a classes socioeconômicas distintas, desenvolvendo atividades variadas, em circunstâncias de comunicação diversificadas, e é natural que essas diferenças, identificadas como sociais ou externas à língua, atuem na maneira de cada falante expressar-se. Sendo assim, a Teoria da Variação Linguística busca correlacionar as variações existentes na fala a diferenças de natureza social, entendendo cada domínio, o linguístico e o social, como fenômenos estruturados e regulares.

Este trabalho objetiva descrever, do ponto de vista perceptivo-auditivo, as características segmentais (vogais e consoantes) da fala de telejornalistas nordestinos das cidades de Maceió - AL e Recife - PE, em emissão espontânea e profissional. Serão feitas análises e comparações das emissões entre sujeitos e cidades, de forma a verificar quais as variantes segmentais mais utilizadas pelos sujeitos em emissão profissional.

\section{Aspectos teórico-metodológicos}

Nos telejornais de rede nacional e local, percebe-se a diversidade de sotaques na fala dos repórteres e apresentadores, mas é notório o cuidado pela suavização das marcas de regionalidade nessa categoria profissional. Bonora (2004) postula que, para as emissoras de televisão, o sotaque não deve chamar mais atenção do que a notícia. A justificativa é que o exagero do regionalismo desvia a atenção do telespectador e contribui para que se perca o mais importante no telejornalismo: o conteúdo da mensagem, a notícia. 
Esta pesquisa foi realizada nas emissoras da Central Globo de Jornalismo e Esporte do Recife - PE e na afiliada da Rede Globo de Maceió - AL. A opção por tais cidades é justificada por retratarem uma pronúncia nordestina, muitas vezes estigmatizada.

A amostra foi composta por quatro telejornalistas de cada cidade pesquisada, totalizando oito sujeitos, que atenderam aos critérios de inclusão abaixo:

a) Fazer parte da equipe de telejornalistas das emissoras escolhidas;

b) Ser repórter ou apresentador de telejornalismo;

c) Ser natural e não ter se ausentado por mais de dois anos da cidade em que atua profissionalmente;

d) Os pais terem sido criados na mesma cidade do falante avaliado;

e) Não apresentar alteração fonoarticulatória e/ou disfonia que alterassem a análise dos aspectos segmentais.

Os telejornalistas avaliados responderam uma "ficha social", proposta por Silva (2003). Esta ficha descreveu o perfil social do sujeito avaliado (sexo, idade, tempo de profissão, nacionalidade e naturalidade do informante e dos pais, cidade onde reside, se faz ou fez fonoaudiologia e há quanto tempo), além de ter possibilitado uma melhor interação com o informante.

A análise das diferenças segmentais da fala dos oito telejornalistas foi estudada em emissão espontânea e profissional, por meio de avaliação perceptivo-auditiva da voz. Para avaliar a emissão natural, como propõe Labov (1983), foi utilizada conversa espontânea sobre experiências pessoais ou situações de perigo que o repórter vivenciou, provocando momentos de fala informal e, portanto, menos preocupado com a forma, pois em situações em que os falantes se sentem observados, por entrevistas, gravações, o comportamento e a fala, normalmente, passam por maior monitoramento.

[...] de repente, eu vi três caras... Passaram, assim, como se tivessem procurando alguma coisa, voltaram e botaram o berro na minha cabeça. Isso é um assalto. Na hora eu pensei que fosse brincadeira.... Aí, assim, o susto, né? Você fica branco. Aí eu passei para o banco do passageiro, dois entraram atrás e um foi dirigindo [...] (Informante MC3). 
[...] peguei o carro e sai... Tava meio escuro e eu não vi o que tinha no meio do caminho...Tinha uma árvore atravessada... Então o carro rodou, rodou, rodou e só parou no muro de uma clínica... A batida foi muito forte... Todo mundo correu pra me socorrer e eu dentro do carro... Pra mim aquilo foi, meu Deus, um sopro de vida, sabe? Porque a batida foi muito feia [...]. (Informante RE4).

Para a emissão profissional, foi solicitado que os repórteres lessem um texto padrão, apresentado em seguida, simulando o estilo de narração do telejornalismo.

"A menina Elaine Dinarte pegou a pasta e colocou dentro da cesta, comprada pela prima Gislaine Bonaparte. Dois minutos depois de guardar a pasta, bateram à porta, o trinco estava aberto, era o cobrador do mercadinho "Cambraia". Ontem, durante o dia, antes de embarcar para Roraima, a tia de Elaine, Dona Gislaide de Farenheite, foi ao mercadinho. A tia de Dinarte perdia tudo, inclusive a lista de compras. Era sempre um sofrimento para ela essa mania de perder as coisas. $\mathrm{Na}$ lista, constavam os itens mamão e banana nanica. A única maneira, nesse período, de evitar desastre maior seria pagar a conta em dinheiro para o Sr. Washington Belarmino Duarte, dono do mercadinho, manter o crédito aberto. Quando Elaine abriu a pasta, que estava dentro da cesta para pegar o dinheiro, teve uma surpresa, ela encontrou o documento da Federal, enviado semana passada por um representante corrupto".

As amostras de fala foram gravadas em computador, no programa de análise acústica de fala Praat ${ }^{3}$, em cabines de gravação de offs ${ }^{4}$ utilizadas nas emissoras, com o intuito de ter uma boa qualidade de áudio, sem interferência de ruído ambiental. Utilizou-se microfone situado a $10 \mathrm{~cm}$ de distância da boca para não ocorrer distorção do som. Primeiramente, foi gravada a amostra da fala espontânea e posteriormente a profissional. Todos os indivíduos tiveram a oportunidade de fazer uma leitura do texto antes da gravação.

O texto estruturado para ser lido em emissão profissional teve como objetivo cobrir os principais fenômenos como potencialmente diferenciadores das diversas variedades. Tais fenômenos podem ser assim sumarizados:

\footnotetext{
${ }^{3}$ Praat é um programa para análise acústica e síntese de fala, desenvolvido por Paul Boersma e David Weenink no Department of Phonetics of the University of Amsterdam.

${ }^{4}$ Voz gravada sem a presença do repórter ou apresentador no vídeo. Notícia coberta.
} 
a) as variações do /S/ e do /R/ pós-vocálico, em coda medial e final;

b) comportamento das consoantes oclusivas alveolares /t/ e /d/ antes de /i/;

c) os contrastes vocálicos $/$ el./ / / e /o/./っ/nas sílabas pretônicas;

d) a nasalidade vocálica optativa.

Para análise perceptivo-auditiva foi realizada a transcrição fonética de todo o material gravado, utilizando o Alfabeto Fonético Internacional.

Os participantes só foram informados claramente sobre os objetivos e procedimentos da pesquisa após a coleta de dados. Este procedimento serviu para diminuir o monitoramento da fala e foram identificados da seguinte forma: a sigla da cidade sucedida por um número de um a quatro, como apresentado em seguida.

Recife: RE1, RE2, RE3 e RE4, participante 1, 2, 3 e 4, respectivamente;

Maceió: MC1, MC2, MC3 e MC4, participante 1, 2, 3 e 4, respectivamente.

Como pode ser visto na tabela 1 , em Recife, participaram três telejornalistas do sexo feminino e um do sexo masculino. Idade média de 36 anos e experiência profissional de 13 anos. Todos fazem ou já fizeram fonoaudiologia.

\begin{tabular}{|c|c|c|c|c|c|}
\hline $\begin{array}{c}\text { Telejornalistas } \\
\text { RECIFE }\end{array}$ & Sexo & Idade & Função & $\begin{array}{c}\text { Tempo de atuação } \\
\text { na área }\end{array}$ & $\begin{array}{c}\text { Faz ou fez } \\
\text { fonoaudiologia }\end{array}$ \\
\hline RE1 & $\mathrm{F}$ & $\begin{array}{c}35 \\
\text { anos }\end{array}$ & Repórter & 13 anos & 6 meses \\
\hline RE2 & $\mathrm{M}$ & $\begin{array}{c}42 \\
\text { anos }\end{array}$ & Repórter & 17 anos & 5 anos \\
\hline RE3 & $\mathrm{F}$ & $\begin{array}{c}37 \\
\text { anos }\end{array}$ & Repórter & 15 anos & 2 meses \\
\hline RE4 & $\mathrm{F}$ & $\begin{array}{c}31 \\
\text { anos }\end{array}$ & Apresentadora & 8 anos & 1 ano \\
\hline
\end{tabular}

Tabela 1: perfil social dos telejornalistas do Recife.

Em Maceió, foram analisados dois do sexo masculino e dois do sexo feminino. Idade média de 27 anos e 4 anos de profissão. Todos os participantes são acompanhados sistematicamente por fonoaudiólogo (tabela 2). 


\begin{tabular}{|c|c|c|c|c|c|}
\hline $\begin{array}{c}\text { Telejornalistas } \\
\text { MACEIÓ }\end{array}$ & Sexo & Idade & Função & $\begin{array}{c}\text { Tempo de } \\
\text { atuação na área }\end{array}$ & $\begin{array}{c}\text { Faz ou fez } \\
\text { fonoaudiologia }\end{array}$ \\
\hline MC1 & M & $\begin{array}{c}27 \\
\text { anos }\end{array}$ & $\begin{array}{c}\text { Apresentador e } \\
\text { repórter }\end{array}$ & 3 anos & 3 anos \\
\hline MC2 & F & $\begin{array}{c}27 \\
\text { anos }\end{array}$ & $\begin{array}{c}\text { Apresentadora e } \\
\text { repórter }\end{array}$ & 5 anos & 3 anos \\
\hline MC3 & M & $\begin{array}{c}28 \\
\text { anos }\end{array}$ & Apresentador & 3 anos & 1 ano \\
\hline MC4 & F & $\begin{array}{c}29 \\
\text { anos }\end{array}$ & Apresentadora & 8 anos & 6 anos \\
\hline
\end{tabular}

Tabela 2: perfil social dos telejornalistas de Maceió.

\section{Descrição e análise dos dados}

A seguir serão expostos os resultados em tabelas e gráficos por variáveis estudadas, separadas por cidades, comparando os sujeitos em ambas as emissões.

\section{Recife - PE}

Os participantes recifenses utilizam, predominantemente, em emissão espontânea, a variante palatalizada em coda medial. $\mathrm{Na}$ fala profissional, observou-se uma substituição do uso pela variante alveolar. Apenas a repórter RE3 permaneceu utilizando as variantes [J] ou [3]. A apresentadora RE4 substituiu em todas as ocorrências da fala as variantes palatalizadas pelas alveolares.

\begin{tabular}{|c|c|c|c|}
\hline Fala espontânea & Ocorrências & {$\left[\int\right][3]$} & {$[\mathrm{s}][\mathrm{z}]$} \\
\hline RE1 & 20 & 19 & 1 \\
\hline RE2 & 20 & 8 & 4 \\
\hline RE3 & 8 & 7 & 2 \\
\hline RE4 & 9 & 1 & {$[\mathrm{~s}][\mathrm{z}]$} \\
\hline Fala profissional & Ocorrências & $43]$ & 12 \\
\hline RE1 & 13 & 11 & 9 \\
\hline RE2 & 13 & - & 2 \\
\hline RE3 & 13 & 13 & 13 \\
\hline RE4 & 13 & 11 & - \\
\hline
\end{tabular}

Tabela 3: Recife- /S/ pós-vocálico em coda medial. 
Observou-se, em emissão espontânea, uma utilização quase equilibrada das variantes palatalizadas e alveolares. Foram realizados sândis com as fricativas alveolares nas palavras seguidas de vogais. Já em emissão profissional, foram utilizadas predominantemente as fricativas alveolares. Apenas a repórter RE3 preferiu o uso das variantes palatalizadas em coda medial e final.

\begin{tabular}{|c|c|c|c|c|}
\hline Fala espontânea & Ocorrências & {$\left[\int\right][3]$} & {$[\mathrm{s}][\mathrm{z}]$} & Sândi $[\mathrm{z}]$ \\
\hline RE1 & 39 & 24 & 13 & 2 \\
\hline RE2 & 37 & 11 & 20 & 6 \\
\hline RE3 & 2 & 2 & - & - \\
\hline RE4 & 26 & 7 & 17 & 2 \\
\hline Fala profissional & Ocorrências & {$\left[\int\right][3]$} & \multicolumn{2}{|c|}{$[\mathrm{s}][\mathrm{z}]$} \\
\hline RE1 & 9 & - & 9 \\
\hline RE2 & 9 & - & \multicolumn{2}{|c|}{1} \\
\hline RE3 & 9 & 8 & 7 \\
\hline RE4 & 9 & 2 & \\
\hline
\end{tabular}

Tabela 4: Recife - /S/ pós-vocálico em coda final.

Uma marca forte do sotaque recifense é a palatalização do /S/ em coda medial e final. Callou, Moraes e Leite (1994) investigaram a fala de cinco capitais, evidenciando que em Porto Alegre e São Paulo há o predomínio da realização alveolar, existindo uma distribuição praticamente idêntica. No Rio de Janeiro e em Recife há o predomínio da realização palatal e em Salvador há uma distribuição homogênea dessas duas variantes. Lira (2001) também referiu a palatalização do /S/ em posição silábica final no Recife e Rio de Janeiro.

Essa palatalização do /S/, segundo Callou e Leite (2002), parece ter sido introduzida no Rio de Janeiro no início do século XIX, trazido pela corte de D. João VI, que era considerada uma pronúncia nobre porque era proveniente da corte portuguesa. Seu uso estendeu-se ao nordeste (Alagoas e Pernambuco), região para qual a pronúncia da antiga capital representava uma norma de prestígio, conforme atesta Marroquim (1996) ao descrever a língua do Nordeste.

Dentre várias cidades, a pronúncia do Rio de Janeiro foi escolhida, no I Congresso de Língua Nacional Cantada, em 1937, como a mais correta. O Rio de Janeiro foi 
identificado, desde a vinda da família real, como o centro mais culto do país e, portanto, o modelo a ser seguido (BERBERIAN, 1995).

Entretanto, a marca mais característica do sotaque carioca, o /S/ palatalizado, passou a ser estigmatizada. Cerca de vinte anos depois do I Congresso de Língua Nacional Cantada, em 1956, nas normas aprovadas pelo I Congresso Brasileiro de Língua Falada no Teatro, já foi referido que o /S/ em final de vocábulo não deveria ser pronunciado com excessivo "chiamento". Provavelmente o que os especialistas da época queriam destacar era que o /S/ deveria ser pronunciado de forma suave, sem excessivo ruído.

No Rio de Janeiro, em 2001, foram realizadas entrevistas com vinte atores de diversas regiões do Brasil, sobre a necessidade de apagamento/suavização das marcas de regionalidade na fala. Pelos resultados deste estudo, pôde-se chegar ao consenso que o /S/ palatalizado do carioca deve ser suavizado. Ficando claro também que há uma tendência entre os informantes a atribuir um valor desqualificativo a determinadas marcas, como foi expresso por um dos entrevistados: "O chiado carioca, no teatro, suja as palavras" (OLIVEIRA, 2001, p. 50). Segundo Lyons (1982), é através dos estereótipos que se estabelece o significado social às variáveis de sotaque e dialeto, e que as reações dos membros de um determinado grupo social, em relação a essas variáveis, podem ser positivas ou negativas.

Lira (2001) refere que o repórter carioca também suaviza seu sotaque para atenuar as diferenças de pronúncia; passa a utilizar o [s] alveolar no lugar do palatalizado para se adequar ao meio. $\mathrm{O}$ mesmo aconteceu com os repórteres e apresentadores desta pesquisa. Em emissão profissional preferiram substituir a pronúncia palatalizada pela alveolar em coda medial e final.

Nas tabelas 5 e 6 encontram-se os dados do /R/ pós-vocálico em coda medial e final. 


\begin{tabular}{|c|c|c|c|c|c|c|}
\hline Fala espontânea & Ocorrências & {$[\mathrm{x}][\mathrm{\gamma}]$} & {$[\mathrm{h}][\mathrm{h}]$} & {$[\mathrm{r}]$} & {$[\mathrm{r}]$} & {$[\mathrm{\jmath}]$} \\
\hline RE1 & 27 & - & 27 & - & - & - \\
\hline RE2 & 7 & - & 7 & - & - & - \\
\hline RE3 & 8 & - & 8 & - & - & - \\
\hline RE4 & 15 & - & 15 & - & - & - \\
\hline Fala profissional & Ocorrências & {$[\mathrm{x}][\mathrm{\gamma}]$} & {$[\mathrm{h}][\mathrm{h}]$} & {$[\mathrm{r}]$} & {$[\mathrm{r}]$} & {$[\mathrm{\jmath}]$} \\
\hline RE1 & 16 & - & 16 & - & - & - \\
\hline RE2 & 16 & - & 16 & - & - & - \\
\hline RE3 & 16 & - & 16 & - & - & - \\
\hline RE4 & 16 & - & 16 & - & - & - \\
\hline
\end{tabular}

Tabela 5: /R/ pós-vocálico em coda medial.

$\mathrm{O} / \mathrm{R} /$ pós-vocálico em coda medial é utilizado pelos recifenses com as variantes [h] [h] em todas as ocorrências de fala espontânea e profissional.

\begin{tabular}{|c|c|c|c|c|c|c|c|c|}
\hline Fala espontânea & Ocorrências & {$[\mathrm{h}][\mathrm{h}]$} & {$[\mathrm{h}][\mathrm{h}]$} & {$[\mathrm{r}]$} & {$[\mathrm{r}]$} & {$[\mathrm{o}]$} & $\begin{array}{c}\text { Sândi } \\
{[\mathrm{r}]}\end{array}$ & $\begin{array}{c}\text { Sândi } \\
{[\mathrm{r}]}\end{array}$ \\
\hline RE1 & 34 & - & 3 & - & - & 30 & 1 & - \\
\hline RE2 & 22 & - & 2 & - & - & 17 & 3 & - \\
\hline RE3 & 9 & - & 1 & - & - & 8 & - & - \\
\hline RE4 & 14 & - & 2 & - & - & 11 & 1 & - \\
\hline $\begin{array}{c}\text { Fala } \\
\text { profissional }\end{array}$ & Ocorrências & {$[\mathrm{h}][\mathrm{h}]$} & {$[\mathrm{h}][\mathrm{h}]$} & {$[\mathrm{r}]$} & {$[\mathrm{r}]$} & {$[\mathrm{o}]$} & $\begin{array}{c}\text { Sândi } \\
{[\mathrm{r}]}\end{array}$ & $\begin{array}{c}\text { Sândi } \\
{[\mathrm{r}]}\end{array}$ \\
\hline RE1 & 11 & - & 3 & - & - & 1 & 7 & - \\
\hline RE2 & 11 & - & 5 & - & - & 2 & 4 & - \\
\hline RE3 & 11 & - & 3 & - & - & 2 & 6 & - \\
\hline RE4 & 11 & - & 2 & - & - & 2 & 7 & - \\
\hline
\end{tabular}

Tabela 6: Recife - /R/ pós-vocálico em coda final.

Em coda final, são eleitas as variantes [h] [h] em ambas as emissões. Foi observado também o zero fonético na fala espontânea e profissional, com um maior número de ocorrências na fala espontânea. Foram realizados sândis com a utilização da variante [r], como pode ser visto na tabela 6.

Callou, Moraes e Leite (1999) analisaram a distribuição do /R/ pós-vocálico em cinco capitais e verificaram que em Recife o índice mais alto é da fricativa aspirada 
(fricativa glotal). Callou \& Leite (2002) descreveram que os falantes do Rio de Janeiro apresentam uma pronúncia do / R/ semelhante aos falantes do Recife por apresentarem uma realização não-vibrante posterior.

$\mathrm{Na}$ tabela 7, os resultados da realização dos fonemas /t/ e /d/ diante de /i/ nos falantes do Recife.

\begin{tabular}{|c|c|c|c|c|c|}
\hline Fala espontânea & Ocorrências & {$[\mathrm{t}]$} & {$[\mathrm{d}]$} & {$\left[\mathrm{t} \int\right]$} & {$[\mathrm{d} 3]$} \\
\hline RE1 & 60 & 30 & 30 & - & - \\
\hline RE2 & 40 & 22 & 11 & 3 & 4 \\
\hline RE3 & 17 & 3 & 10 & 2 & 2 \\
\hline RE4 & 35 & 19 & 13 & 1 & 2 \\
\hline Fala profissional & Ocorrências & {$[\mathrm{t}]$} & {$[\mathrm{d}]$} & {$\left[\mathrm{t} \int\right]$} & {$[\mathrm{d} 3]$} \\
\hline RE1 & 29 & 2 & 6 & 8 & 13 \\
\hline RE2 & 29 & - & 8 & 10 & 11 \\
\hline RE3 & 29 & - & - & 10 & 19 \\
\hline RE4 & 29 & - & - & 10 & 19 \\
\hline
\end{tabular}

Tabela 7: Recife - /t/ e /d/ diante de /i/.

Em emissão espontânea, o /t/ e o /d/ diante de /i/ foram predominantemente realizados com as variantes oclusivas alveolares. Já na fala profissional, houve o predomínio do uso das variantes palatalizadas. Um dado interessante a destacar é que a participante RE1 utilizou em todas as ocorrências da fala espontânea as variantes alveolares [t] e [d] e na fala profissional houve o predomínio das palatalizadas [t]] e [d3]. As telejornalistas RE3 e RE4 utilizaram em toda a fala profissional as variantes palatalizadas.

$\mathrm{Na}$ maior parte dos estados do nordeste, essas oclusivas alveolares se mantêm diante da vogal /i/, ocorrendo no Rio Grande do Norte, Paraíba, Pernambuco, Alagoas e Sergipe (ADANT, 1989). Lira (2001) e Bonora (2004) referiram a pronúncia da variante oclusiva alveolar para o /t/ e /d/ diante do /i/ no dialeto do Recife.

Essa é outra marca típica do sotaque pernambucano. Uma variante que mostrou não ser aceita pelo grupo pesquisado. Os telejornalistas recifenses utilizaram predominantemente na fala espontânea as variantes oclusivas alveolares. Já em emissão 
profissional, comprovou-se uma quase total modificação da pronúncia pelas variantes palatalizadas.

Um fato que merece destaque diz respeito às variáveis tempo de profissão e acompanhamento fonoaudiológico. Essas variáveis não foram relevantes para o aumento do uso da palatalização nos informantes avaliados. A informante RE2 tem 17 anos de atuação como repórter e faz há cinco anos fonoaudiologia, e ainda assim, realizou algumas vezes na fala profissional as variantes oclusivas alveolares. Já as telejornalistas RE3 e RE4 fazem o acompanhamento com fonoaudiólogo há menos tempo e palatalizaram em todas as ocorrências da fala profissional.

A tabela 8 traz os contrastes vocálicos na fala dos informantes pernambucanos.

\begin{tabular}{|c|c|c|c|c|c|c|}
\hline Fala espontânea & $\begin{array}{c}\text { Ocorrências } \\
\square\end{array}$ & {$[\varepsilon]$} & {$[\mathrm{e}]$} & Ocorrências & {$[\mathrm{\jmath}]$} & {$[\mathrm{o}]$} \\
\hline RE1 & 14 & 10 & 4 & 6 & 6 & - \\
\hline RE2 & 26 & 17 & 9 & 8 & 6 & 2 \\
\hline RE3 & 3 & 1 & 2 & 2 & 1 & 1 \\
\hline RE4 & 9 & 3 & 6 & 5 & 3 & 2 \\
\hline Fala profissional & Ocorrências & {$[\varepsilon]$} & {$[\mathrm{e}]$} & Ocorrências & {$[$ [ ] } & {$[\mathrm{o}]$} \\
\hline RE1 & 17 & 8 & 9 & 5 & 1 & 4 \\
\hline RE2 & 17 & 9 & 8 & 5 & 1 & 4 \\
\hline RE3 & 17 & 4 & 13 & 5 & - & 5 \\
\hline RE4 & 17 & 3 & 14 & 5 & - & 5 \\
\hline
\end{tabular}

Tabela 8: Recife - contrastes vocálicos.

Observou-se uma maior realização das vogais abertas na sílaba pretônica em emissão espontânea na fala dos recifenses. Já na profissional, destacaram-se as vogais fechadas (tabela 8). A apresentadora RE4 utilizou mais as vogais fechadas em ambas as emissões.

Nos resultados da pesquisa de Lira (2001), foi comprovado que a realização alta das vogais médias /e, o/, em posição pretônica, é predominante nos sotaques do sudeste, enquanto que na cidade de Recife, a preferência é por uma pronúncia aberta. 
No que diz respeito à consciência linguística do falante, os aspectos linguísticos salientes são os que são mais facilmente imitados por um falante não nativo, segundo Trudgill (1986). Quando o carioca imita o nordestino, os traços vocálicos ficam bem acentuados, demonstrando, por isso, ser uma marca forte e estigmatizada (MARQUES, 2006).

A marca bem característica do nordeste são as vogais pretônicas realizadas de forma aberta, que servem de imitação pejorativa e, muitas vezes, inadequada por falantes de outras regiões do Brasil.

É comum observar atores que não são nordestinos desempenhando papéis de nordestinos, falando com uma pronúncia que distorce as marcas do sotaque do nordeste, principalmente no que se refere ao emprego das vogais médias pretônicas, cuja predominância de realização aberta passa a ocorrer de forma indiscriminada e sem critério (LIRA, 2001).

Marques (2006) pesquisou como se processou a acomodação dialetal na fala de migrantes paraibanos que residem no Rio de Janeiro há, no mínimo, um ano. O objeto de análise linguística foi a variação das vogais médias pretônicas /e/ e /o/, que se constitui como um dos pontos de divergência entre os dois dialetos brasileiros.

Na pesquisa, foi constatado que a partir dos cinco anos de residência no Rio de Janeiro, o contato com o carioca vai ocasionando uma mudança da variante $[\varepsilon]$ pela [e] com o passar do tempo. E verificado também que os falantes com mais tempo de exposição às normas escolares são mais sensíveis ao processo de acomodação. A observação individual dos falantes permitiu constatar, no geral, que aqueles que fazem do modo de vida e fala cariocas um "modelo de projeção de identidade", são os que mais facilmente se acomodam ao outro sotaque.

Esse comportamento social, segundo Calvet (2002), pode desenvolver dois tipos de consequência sobre os comportamentos linguísticos: um se refere ao modo como os falantes encaram sua própria fala, outro se refere às reações dos falantes ao falar dos outros. Em um caso, se valorizará sua prática linguística ou se tentará, ao invés, modificá-la para conformá-la a um modelo prestigioso; no outro, as pessoas serão julgadas segundo seu modo de falar. 
A seguir, na tabela 9, são mostrados os resultados sobre o processo de nasalidade nos telejornalistas recifenses.

\begin{tabular}{|c|c|c|c|c|c|c|c|c|c|c|}
\hline $\begin{array}{c}\text { Fala } \\
\text { profissional }\end{array}$ & Elaine & Gislaine & Roraima & Elaine & mania & mamão & banana & nanica & Elaine & maneira \\
\hline RE1 & & $\mathrm{X}$ & & & $\mathrm{X}$ & $\mathrm{X}$ & $\mathrm{X}$ & $\mathrm{X}$ & & $\mathrm{X}$ \\
\hline RE2 & & & & & $\mathrm{X}$ & $\mathrm{X}$ & $\mathrm{X}$ & $\mathrm{X}$ & & $\mathrm{X}$ \\
\hline RE3 & & & & & $\mathrm{X}$ & $\mathrm{X}$ & $\mathrm{X}$ & $\mathrm{X}$ & & $\mathrm{X}$ \\
\hline RE4 & & & & & $\mathrm{X}$ & $\mathrm{X}$ & $\mathrm{X}$ & $\mathrm{X}$ & & $\mathrm{X}$ \\
\hline
\end{tabular}

Tabela 9: Recife - Nasalidade.

$\mathrm{Na}$ fala profissional, os telejornalistas recifenses utilizaram o processo de nasalidade optativa nas palavras: [mã'nia, mã'mãw, bã'nãna, nã'nika, mã'nejra]. Apenas o sujeito RE2 emitiu na fala espontânea uma palavra que ocorre o processo de nasalidade: [3ã'nejru].

Os recifenses utilizaram o processo de nasalidade optativa apenas nas sílabas pretônicas, com exceção da repórter RE1 que nasalizou a palavra [ع'lãjni].

A nasalidade é mais perceptível auditivamente com a vogal central baixa /a/. Com as vogais médias /e/ e /o/ e as vogais altas /i/ e /u/ às vezes é difícil de identificar se a nasalidade ocorre ou não. Com a vogal /a/ ocorre uma alteração significativa do trato vocal quando o véu palatino abaixa-se para produzir uma vogal nasal. Com as outras vogais a alteração do trato vocal não é significativa. Além do mais, o fato de a nasalidade não causar diferença de significado entre palavras interfere na percepção desses segmentos pelos falantes (SILVA, 2003).

Não foi verificado o processo de nasalidade optativa em outras vogais em emissão espontânea, como, por exemplo, nas palavras, funeral [fune'raw] - [fũne'raw], final [fi'naw] - [fînaw], bonança [bo'nãsa] - [bõ'nãsa], onde também seria possível ocorrer o processo. No texto padrão construído, só foram incluídas palavras com a vogal central baixa $/ \mathrm{a} /$. 


\section{Maceió - AL}

Foi constatado que o grupo de telejornalistas de Maceió é o mais novo em idade e experiência profissional. Essa realidade é comum em cidades e emissoras pequenas. A emissora de Maceió é uma afiliada da Rede Globo, muitos desses profissionais passam pouco tempo na empresa, galgando e conseguindo espaços em afiliadas maiores, nas próprias sedes da TV Globo (Rio de Janeiro, São Paulo, Belo Horizonte, Brasília e Recife) ou em outras empresas.

Em Maceió, foram utilizadas as variantes palatalizadas em coda medial apenas diante do fonema / $\mathrm{t} /$ na fala espontânea. $\mathrm{Na}$ profissional, quase todos os participantes MC2, MC3, MC4 utilizaram as variantes alveolares.

\begin{tabular}{|c|c|c|c|}
\hline Fala espontânea & Ocorrências & {$\left[\int\right][3]$} & {$[\mathrm{s}][\mathrm{z}]$} \\
\hline MC1 & 11 & 10 & 1 \\
\hline MC2 & 4 & 1 & 3 \\
\hline MC3 & 12 & 8 & 4 \\
\hline MC4 & 16 & {$\left[\int\right][3]$} & {$[\mathrm{s}][\mathrm{z}]$} \\
\hline Fala profissional & Ocorrências & 12 & 1 \\
\hline MC1 & 13 & - & 13 \\
\hline MC2 & 13 & - & 13 \\
\hline MC3 & 13 & - & 13 \\
\hline MC4 & 13 & & \\
\hline
\end{tabular}

Tabela 10: Maceió- /S/ pós-vocálico em coda medial.

Em coda final, o /S/ pós-vocálico foi mais pronunciado com as variantes alveolares em ambas as emissões. 


\begin{tabular}{|c|c|c|c|c|}
\hline Fala espontânea & Ocorrências & {$\left[\int\right][3]$} & {$[\mathrm{s}][\mathrm{z}]$} & Sândi [z] \\
\hline MC1 & 18 & 3 & 15 & - \\
\hline MC2 & 10 & - & 10 & - \\
\hline MC3 & 15 & 2 & 13 & - \\
\hline MC4 & 43 & - & 43 & 8 \\
\hline Fala profissional & Ocorrências & {$\left[\int\right][3]$} & \multicolumn{2}{|c|}{ [s] [z] } \\
\hline MC1 & 9 & 1 & 9 \\
\hline MC2 & 9 & - & \multicolumn{2}{|c|}{9} \\
\hline MC3 & 9 & - & \multicolumn{2}{|c|}{9} \\
\hline MC4 & 9 & & \\
\hline
\end{tabular}

Tabela 11: Maceió - /S/ pós-vocálico em coda final.

Foi observado que em emissão profissional os alagoanos, assim como os recifenses, modificaram a pronúncia palatalizada pela alveolar. Isso mostra mais uma vez que essa variante é considerada de pouco prestígio.

Callou, Moraes e Leite (1999) e Marroquim (1996) fazem referência à pronúncia palatalizada do /S/ em coda nos falantes de Alagoas.

Na tabelas 12 e 13 seguem os dados sobre o /R/ pós-vocálico em coda medial e final.

\begin{tabular}{|c|c|c|c|c|c|c|}
\hline Fala espontânea & Ocorrências & {$[\mathrm{x}][\gamma]$} & {$[\mathrm{h}][\mathrm{h}]$} & {$[\mathrm{r}]$} & {$[\mathrm{r}]$} & {$[\mathrm{o}]$} \\
\hline MC1 & 11 & - & 11 & - & - & - \\
\hline MC2 & 3 & - & 3 & - & - & - \\
\hline MC3 & 6 & - & 6 & - & - & 1 \\
\hline MC4 & 17 & - & 17 & - & - & {$[$ ] } \\
\hline Fala profissional & Ocorrências & {$[\mathrm{x}][\gamma]$} & {$[\mathrm{h}][\mathrm{h}]$} & {$[\mathrm{r}]$} & {$[\mathrm{r}]$} & - \\
\hline MC1 & 16 & - & 16 & - & - & - \\
\hline MC2 & 16 & - & 15 & - & 1 & - \\
\hline MC3 & 16 & - & 16 & - & - & - \\
\hline MC4 & 16 & - & 16 & - & - & \\
\hline
\end{tabular}

Tabela 12: Maceió - /R/ pós-vocálico em coda medial. 
As fricativas glotais [h] [h] são utilizadas pelos maceioenses pesquisados, no contexto de coda medial, em ambas as emissões.

\begin{tabular}{|c|c|c|c|c|c|c|c|c|}
\hline $\begin{array}{c}\text { Fala } \\
\text { espontânea }\end{array}$ & Ocorrências & {$[\mathrm{x}][\mathrm{\gamma}]$} & {$[\mathrm{h}][\mathrm{h}]$} & {$[\mathrm{r}]$} & {$[\mathrm{r}]$} & {$[\mathrm{o}]$} & $\begin{array}{c}\text { Sândi } \\
{[\mathrm{r}]}\end{array}$ & Sândi [r] \\
\hline MC1 & 17 & - & 3 & - & - & 14 & - & - \\
\hline MC2 & 8 & - & 1 & 1 & - & 4 & - & - \\
\hline MC3 & 10 & - & 1 & - & - & 9 & - & - \\
\hline MC4 & 41 & - & 12 & - & - & 29 & - & - \\
\hline Fala & Ocorrências & {$[\mathrm{x}][\gamma]$} & {$[\mathrm{h}][\mathrm{h}]$} & {$[\mathrm{r}]$} & {$[\mathrm{r}]$} & {$[\mathrm{\jmath}]$} & Sândi & Sândi [r] \\
\hline profissional & 11 & - & 3 & - & - & 1 & 7 & - \\
\hline MC1 & 11 & - & 3 & - & - & 1 & 7 & - \\
\hline MC2 & 11 & - & 4 & - & - & - & 7 & - \\
\hline MC3 & 11 & - & 4 & - & - & - & 7 & - \\
\hline MC4 & & & & & & {$[\mathrm{r}]$} & \\
\hline
\end{tabular}

Tabela 13: Maceió - /R/ pós-vocálico em coda final.

Assim como na capital pernambucana, o apagamento do /R/ em coda final aconteceu mais vezes. Em seguida, foram eleitas as fricativas glotais, usadas também pelos informantes do Recife. Já na fala profissional, quase não foi verificado o apagamento do /R/ nesse contexto. Ocorreram as junções previstas no texto e a variante utilizada também foi o tepe.

Payão (2004) encontrou a realização da variante fricativa glotal na fala espontânea de crianças alagoanas. E Cardoso (2005) também referiu em sua pesquisa a variante $[\mathrm{h}]$ na fala de informantes adultos alagoanos. 


\begin{tabular}{|c|c|c|c|c|c|}
\hline Fala espontânea & Ocorrências & {$[\mathrm{t}]$} & {$[\mathrm{d}]$} & $[\mathrm{t}]]$ & {$[\mathrm{d} 3]$} \\
\hline MC1 & 27 & 12 & 13 & 2 & - \\
\hline MC2 & 7 & - & 2 & 2 & 3 \\
\hline MC3 & 18 & 9 & 9 & - & - \\
\hline MC4 & 37 & 15 & 17 & 2 & 3 \\
\hline Fala profissional & Ocorrências & {$[\mathrm{t}]$} & {$[\mathrm{d}]$} & $[\mathrm{t}]]$ & {$[\mathrm{d} 3]$} \\
\hline MC1 & 30 & 2 & 7 & 9 & 12 \\
\hline MC2 & 29 & - & - & 10 & 19 \\
\hline MC3 & 29 & 5 & - & 9 & 15 \\
\hline MC4 & 29 & - & - & 10 & 19 \\
\hline
\end{tabular}

Tabela 14: Maceió - /t/e /d/ diante de /i/.

Os sujeitos MC1, MC3 e MC4 utilizaram predominantemente, na fala espontânea, as variantes alveolares [t] e [d], só a participante MC2 priorizou as pronúncias palatalizadas [t]] e [d3]. O contrário aconteceu em emissão profissional, uma vez que todos os apresentadores realizaram com predomínio as variantes palatalizadas, assim como no Recife.

Santos (1997) traçou algumas considerações sobre a ocorrência das oclusivas /t/ e /d/ na fala de Maceió. Verificou que as ocorrências de /t/ como oclusiva alveolar superaram majoritariamente as realizações palatalizadas. $\mathrm{O}$ fonema /d/ não apresentou palatalização em nenhum dos contextos analisados, mantendo-se como oclusiva. A maior frequência da palatalização da oclusiva / $\mathrm{t}$ / ocorreu quando precedida pela semivogal [j] e

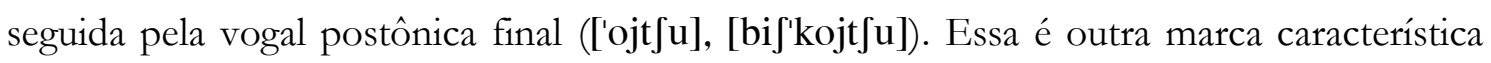
do sotaque maceioense, mas que não foi encontrada na fala espontânea dos telejornalistas alagoanos. No texto padrão para ser lido em emissão profissional também não foi enfocada essa variante.

Os jornalistas de Maceió e Recife modificaram de forma semelhante em ocorrência as variantes alveolares pelas palatalizadas. Os resultados mostraram que essa é outra variante sem prestígio. Em Maceió, a variável tempo de profissão foi mais relevante na produção da variante palatalizada, tendo em vista que as apresentadoras MC2 e MC4 palatalizaram mais em ambas as emissões. Já o tempo de acompanhamento com fonoaudiólogo parece não interferir de forma definitiva no processo. O apresentador MC1, 
por exemplo, faz há 3 anos fonoaudiologia e manteve as realizações das oclusivas alveolares na fala profissional e o apresentador MC3, que tem apenas 1 ano de acompanhamento, apresentou menos ocorrências das oclusivas alveolares na fala profissional (ver dados na tabela 1$)$.

Adant (1989) analisou as alterações ocorridas na pronúncia de falantes adultos procedentes de Alagoas e residentes em Brasília há, pelo menos, 10 anos. A regra de manutenção das oclusivas alveolares /t/ e /d/ diante de /i/ é categórica em Alagoas. A pesquisa permitiu concluir que as oclusivas alveolares /t/ e /d/ apresentaram mudanças mais significativas que as outras variáveis nos migrantes alagoanos. Como apresentado por Marques (2006), um dos aspectos linguísticos mais salientes da fala dos cariocas sentidos pelos nordestinos é a realização das oclusivas alveolares diante de /i/, talvez por isso essas variantes foram as que mais sofreram mudança, passando de alveolares a palatalizadas.

Em relação às vogais, os telejornalistas de Maceió priorizaram as vogais abertas [ع] e [e] na fala espontânea e na fala profissional realizaram de forma variada. Um dado interessante a destacar é que os apresentadores MC1, MC2 e MC3 pronunciaram o /e/ de Elaine, fechado, e não aberto, como a apresentadora MC4 e todos os telejornalistas do Recife. A participante MC2 foi a única que usou poucas vezes as vogais abertas na fala profissional. Os contrastes vocálicos na fala dos maceioenses serão apresentados a seguir.

\begin{tabular}{|c|c|c|c|c|c|c|}
\hline Fala espontânea & Ocorrências & {$[\varepsilon]$} & {$[\mathrm{e}]$} & Ocorrências & {$[$ [0] } & {$[\mathrm{o}]$} \\
\hline MC1 & 18 & 18 & - & 3 & 3 & - \\
\hline MC2 & 12 & 6 & 6 & 2 & 1 & 1 \\
\hline MC3 & 7 & 5 & 2 & 5 & 5 & - \\
\hline MC4 & 17 & 14 & 3 & 22 & 22 & - \\
\hline Fala profissional & Ocorrências & {$[\varepsilon]$} & {$[\mathrm{e}]$} & Ocorrências & {$[$ [0] } & {$[\mathrm{o}]$} \\
\hline MC1 & 17 & 9 & 8 & 5 & - & 5 \\
\hline MC2 & 17 & 4 & 13 & 5 & 1 & 4 \\
\hline MC3 & 17 & 11 & 6 & 5 & 2 & 3 \\
\hline MC4 & 17 & 9 & 8 & 5 & 2 & 3 \\
\hline
\end{tabular}

Tabela 15: Maceió - contrastes vocálicos. 
Em relação a essas variantes em cruzamento com as variáveis tempo de atuação profissional e acompanhamento com fonoaudiólogo, a apresentadora MC4 foi a que mais utilizou as vogais abertas em posição pretônica, mesmo sendo a que faz mais tempo acompanhamento com fonoaudiólogo, 6 anos, e a que tem mais tempo de carreira, 8 anos de atuação como apresentadora de telejornal.

\begin{tabular}{|c|c|c|c|c|c|c|c|c|c|c|}
\hline $\begin{array}{c}\text { Fala } \\
\text { profissional }\end{array}$ & Elaine & Gislaine & Roraima & Elaine & mania & mamão & banana & nanica & Elaine & Maneira \\
\hline MC1 & $\mathrm{X}$ & $\mathrm{X}$ & & $\mathrm{X}$ & $\mathrm{X}$ & $\mathrm{X}$ & $\mathrm{X}$ & $\mathrm{X}$ & $\mathrm{X}$ & $\mathrm{X}$ \\
\hline MC2 & $\mathrm{X}$ & $\mathrm{X}$ & & $\mathrm{X}$ & $\mathrm{X}$ & $\mathrm{X}$ & $\mathrm{X}$ & $\mathrm{X}$ & $\mathrm{X}$ & $\mathrm{X}$ \\
\hline MC3 & $\mathrm{X}$ & $\mathrm{X}$ & & $\mathrm{X}$ & $\mathrm{X}$ & $\mathrm{X}$ & $\mathrm{X}$ & $\mathrm{X}$ & $\mathrm{X}$ & $\mathrm{X}$ \\
\hline MC4 & & & & & $\mathrm{X}$ & $\mathrm{X}$ & $\mathrm{X}$ & $\mathrm{X}$ & & $\mathrm{X}$ \\
\hline
\end{tabular}

Tabela 16: Maceió - Nasalização.

Em Maceió, ocorreu o processo de nasalidade nas palavras Elaine e Gislaine em três dos sujeitos pesquisados, além das palavras mania, mamão, banana, nanica e maneira. Não foi encontrada nenhuma ocorrência do processo de nasalidade optativa na fala espontânea dos sujeitos de Maceió.

Cruzando os resultados das realizações do processo de nasalidade optativa em Maceió e Recife, foi verificada a nasalidade nas sílabas pretônicas das palavras mania, mamão, banana, nanica e maneira. Três dos quatro sujeitos de Maceió nasalizaram as palavras Elaine e Gislaine na sílaba tônica, apenas uma repórter do Recife nasalizou a palavra Gislaine. A vogal da sílaba medial da palavra Roraima não foi nasalizada por nenhum dos participantes maceioenses e recifenses.

Essa é outra marca do sotaque recifense e maceioense, a nasalidade optativa das vogais em posição pretônica. Os telejornalistas avaliados não alteraram essa característica, mas utilizaram também esse processo, em emissão profissional, nas sílabas tônicas de algumas palavras que são características do sotaque carioca e paulista.

Os telejornalistas do Recife e Maceió modificaram sua pronúncia na fala profissional para se adequar ao modelo prestigioso da região sudeste, mesmo sabendo que atualmente na Central Globo de Telejornalismo e Esporte é aceita a diversidade de sotaques, segundo Bernardes (2004). Para a apresentadora e editora do Jornal Nacional, o 
mais importante é ter uma pronúncia clara e precisa. Os repórteres não devem falar igual. Manter sotaques e estilo é fundamental.

Este é um ponto controverso para os telejornalistas, para os fonoaudiólogos e provavelmente para a emissora. Por um lado, o profissional quer um espaço ou quer mantê-lo, quer estar dentro dos padrões de comunicação que são mais aceitos e mostramse mais eficientes para a sociedade; e, por outro, não quer modificar suas marcas de regionalidade, delimitadora de suas origens.

O fonoaudiólogo tem o compromisso com a empresa de melhorar a comunicação global desses telejornalistas e manter a saúde vocal. Preservar o regionalismo, limitando os exageros, também é função do fonoaudiólogo. Mas o que fazer quando o repórter quer continuar com o sotaque exagerado? Incentivar essa escolha ou insistir na suavização ou modificação das marcas caracterizadoras do sotaque da sua região? Esses são alguns questionamentos.

O sotaque atribui personalidade ao telejornalista e à matéria, mas é bem verdade que o sotaque exagerado do outro pode incomodar, afastar e interferir nas relações interpessoais e profissionais, já que os códigos e suas manifestações são diferentes. Afinal, para que a comunicação ocorra de maneira plena é necessário empatia, aproximação. As fonoaudiólogas das emissoras Globo de São Paulo e Rio de Janeiro, Kyrillos, Feijó e Cotes (2002), e da Globo Recife, Bonora (2004), relatam que atualmente há repórteres com pronúncias características de suas regiões de origem, mas o sotaque é perceptível e suave, não devendo chamar mais atenção do que a mensagem.

A emissora quer excelência no padrão de qualidade para garantir a melhor audiência. Quer que o telespectador se identifique com os repórteres da sua região para que transmita mais veracidade à notícia, mas também não quer ruídos na comunicação.

Mas um ponto tem que ficar claro. Atualmente, no telejornalismo, mais importante do que ter um "vozeirão" e um sotaque neutro, é ser um bom comunicador. No final da década de 1980 houve grande mudança no formato dos telejornais e aquele padrão mais estereotipado de apresentador, com voz impostada e certo distanciamento, foi sendo substituído pela necessidade de um profissional que utilizasse a comunicação de maneira natural, aproximando-se do público e marcando um estilo próprio de atuação (ALICE MARIA, 2004). Atualmente, o telejornalista deve saber, sobretudo, usar ao máximo suas 
potencialidades e ser espontâneo. Deve chamar a atenção pela forma natural, clara e interativa de transmitir a notícia.

Para conseguir este objetivo, o apresentador ou repórter deve usar os recursos vocais - prosódicos (qualidade vocal, entoação, pausa, padrão de acento e duração, velocidade de fala, ritmo) e os não verbais (expressões faciais, gestos, postura corporal e meneios de cabeça), de modo que estes sempre contribuam para valorizar o texto. $\mathrm{O}$ carisma, a originalidade, a criatividade, o poder de síntese e a improvisação também fazem parte do rol de características que o telejornalista deve buscar para desenvolver um bom trabalho (SÓSTENES \& SOUTO, 2004; SÓSTENES, PINHO \& CAMARGO, 2007). Então, o sotaque não é mais importante do que esses outros requisitos, mas quando o profissional não consegue se comunicar bem, o sotaque exagerado pode ser um empecilho para que ele consiga se adequar ao meio.

\section{Considerações finais}

A partir da análise descritiva da amostra, foram encontradas as seguintes realizações:

Emissão espontânea - Recife

- /S/ pós-vocálico em coda medial: variantes predominantes - palatalizadas [ [ ,3] e final: variantes predominantes palatalizadas [ $[, 3]$;

- /R/ pós-vocálico em coda medial: variantes predominantes - fricativas glotais [ h, h] e final: variantes predominantes - fricativas glotais [ $h, h]$ e o zero fonético $[\varnothing]$;

- /t/e /d/diante de /i/: variantes predominantes - alveolares [t, d];

- Contrastes vocálicos nas sílabas pretônicas: variantes predominantes - vogais abertas $[\varepsilon, \mathrm{e}]$. 
Emissão profissional - Recife

- /S/ pós-vocálico em coda medial: variantes predominantes - alveolares [s, z] e final: variantes predominantes - alveolares $[\mathrm{s}, \mathrm{z}]$;

- /R/ pós-vocálico em coda medial: variantes predominantes - fricativas glotais $[\mathrm{h}, \mathrm{h}]$ e final: variantes predominantes - fricativas glotais [ $h, \mathrm{~h}]$;

- /t/ e /d/ diante de /i/: variantes predominantes - palatalizadas [ t $\left.\int, \mathrm{d}_{3}\right]$;

- Contrastes vocálicos nas sílabas pretônicas: variantes predominantes - vogais fechadas [ e, o];

- Nasalidade optativa nas vogais pretônicas.

Emissão espontânea - Maceió

- /S/ pós-vocálico em coda medial: variantes predominantes - palatalizadas $\left[\int, 3\right]$ diante apenas do fonema $/ \mathrm{t} /$, e final: variantes predominantes alveolares $[\mathrm{s}, \mathrm{z}]$

- /R/ pós-vocálico em coda medial: variantes predominantes - fricativas glotais [ h, h] e final: variantes predominantes - fricativas glotais [ $h, h]$ e o zero fonético $[\varnothing]$;

- /t/ e /d/diante de /i/: variantes predominantes - alveolares [t, d];

- Contrastes vocálicos nas sílabas pretônicas: variantes predominantes - vogais abertas $[\varepsilon, o]$.

Emissão profissional - Maceió

- /S/ pós-vocálico em coda medial: variantes predominantes - alveolares [s, z] e final: variantes predominantes - alveolares $[\mathrm{s}, \mathrm{z}]$;

- /R/ pós-vocálico em coda medial: variantes predominantes - fricativas glotais [ h, h] e final: variantes predominantes - fricativas glotais [ $h, \mathrm{~h}]$;

- /t/ e /d/diante de /i/: variantes predominantes - palatalizadas [t $\left.\int, \mathrm{d} 3\right]$; 
- Contrastes vocálicos nas sílabas pretônicas: variantes predominantes - vogais fechadas [e, o];

- Predomínio da nasalidade optativa nas vogais pretônicas.

Os repórteres e apresentadores das cidades do Recife e Maceió modificaram suas pronúncias de origem na fala profissional para se adequar ao meio, já em emissão espontânea, houve um “despoliciamento” em manter o padrão telejornalístico.

O sotaque não deve ser visto como uma diferença incômoda, mas como um traço da identidade do falante, algo que vai além das possibilidades da fala, pois nenhum sotaque é considerado melhor ou pior, certo ou errado. Cada pessoa fala com suas características próprias, segundo o meio social de onde provém e a região onde nasceu e vive. Respeitar a diferença, considerando-a uma riqueza, deve ser a postura básica do fonoaudiólogo. O respeito pela individualidade é fator preponderante para que não seja criada uma máquina, um robô. A riqueza humana está na diversidade, pela qual se deve zelar.

\section{Referências}

ALICE MARIA. História da fonoaudiologia no telejornalismo. In: KYRILLOS, L.; FEIJÓ, D. Fonoaudiologia e Telejornalismo - Baseado no III Encontro de Fonoaudiologia da Central Globo de Telejornalismo. Rio de Janeiro: Revinter, 2004, p. 1-3.

ADANT, J. Difusão dialetal: o caso dos alagoanos em Brasília. In: TARALLO, F. (Org.). Fotografias sociolingüísticas. Campinas: Pontes, Editora da UNICAMP, 1989, p. 181197.

\section{ANAIS DO PRIMEIRO CONGRESSO BRASILEIRO DE LÍNGUA FALADA NO TEATRO. Rio de Janeiro: MEC, 1958, p. 95-479.}

BERBERIAN, A. P. Fonoaudiologia e educação: um encontro histórico. São Paulo: Plexus, 1995.

BERNARDES, F. Depoimento. In: KYRILLOS, L.; FEIJÓ, D. Fonoaudiologia e Telejornalismo - Baseado no III Encontro de Fonoaudiologia da Central Globo de Jornalismo. Rio de Janeiro: Revinter, 2004.

BONORA, M. Sotaque x Telejornalismo. In: KYRILLOS, L.; FEIJÓ, D. Fonoaudiologia e Telejornalismo - Baseado no III Encontro de Fonoaudiologia da Central Globo de Jornalismo. Rio de Janeiro: Revinter, 2004, p. 81-93. 
CALLOU, D.; MORAES, J.; LEITE, Y. A realização das consoantes pós-vocálicas no português do Brasil. Trabalho não publicado, 1994.

Processo de enfraquecimento consonantal no Português do Brasil. In:

ABAURRE, M. B. (Org.). Gramática do Português Falado. Campinas: Editora Unicamp, 1999.

CALLOU, D.; LEITE, Y. Como falam os brasileiros. Rio de Janeiro: Jorge Zahar Editora, 2002.

CALVET, L. J. Sociolinguística: uma introdução crítica. São Paulo: Parábola, 2002.

CARDOSO, J. H. C. A nativização de termos de informática do inglês no português brasileiro: uma análise fonológica. Dissertação (Mestrado em Linguística). Maceió:

Universidade Federal de Alagoas, 2005.

KYRILLOS, L.; FEIJÓ, D.; COTES, C. A fonoaudiologia no telejornalismo. In: FERREIRA, L.; ANDRADA E SILVA, M. Saúde Vocal: práticas fonoaudiológicas. São Paulo: Roca, 2002, p. 251-266.

LABOV, W. Modelos sociolinguísticos. Madri: Ediciones Cátedra, 1983.

LIRA, Z. S. Descrição fonética das características segmentais dos sotaques de

Recife, Rio de Janeiro e São Paulo: análise perceptivo-auditiva e acústica. Dissertação de Mestrado. São Paulo: Pontifícia Universidade Católica - SP, 2001.

LYONS, J. Linguagem e Linguística. Rio de Janeiro: Editora Zahar, 1982.

MANUAL DE TELEJORNALISMO DA CENTRAL GLOBO DE JORNALISMO. Rio de Janeiro, 1985.

MARQUES, S. M. O. As vogais médias pretônicas em situação de contato dialetal. Tese (Doutorado em Letras Vernáculas). Rio de Janeiro: Universidade Federal do Rio de Janeiro, 2006.

MARROQUIM, M. A Língua do Nordeste: Pernambuco e Alagoas. 3 ed. Curitiba: HD Livros Editora, 1996.

OLIVEIRA, M. C. As marcas de regionalidade em atores de teatro. Revista da Sociedade Brasileira de Fonoaudiologia, ano 6, $\mathrm{n}^{\mathrm{o}}$ 2, 2001, p. 47-53.

PAYÃO, L. M. C. Desvios fonológicos em crianças da educação infantil: uma análise a partir dos traços distintivos. Dissertação (Mestrado em Linguística). Maceió: Universidade Federal de Alagoas, 2004.

SANTOS, L. F. Realização das oclusivas /t/ e /d/ na fala de Maceió. In: Moura, D. (Org.). Variação e ensino. Maceió: EDUFAL, 1997, p. 69-89.

SILVA, G. M. O. Coleta de dados. In: MOLLICA, M. C.; BRAGA, M. L. (Org.).

Introdução à Sociolinguística: o tratamento da variação. São Paulo: Contexto, 2003, p. 117-133. 
SILVA, T. C. Fonética e fonologia do português: roteiro de estudos e guia de exercícios. São Paulo: Contexto, 2003.

SÓSTENES, G.; SOUTO, M. A. C . Narração de um grupo de telejornalistas - análise pré e pós-atuação fonoaudiológica. In: KYRILLOS, L.; FEIJÓ, D. (Org.). Fonoaudiologia e telejornalismo baseado no III Encontro Nacional de Fonoaudiologia da CGJ. Rio de Janeiro: Revinter, 2004, p. 127-151.

SÓSTENES, G.; PINHO, S. M. R.; CAMARGO, Z. A. Atuação fonoaudiológica no telejornalismo. In: PINHO, S. M. R. (Org.). Temas em voz profissional. Rio de Janeiro: Revinter, 2007.

TRUDGILL, P. Dialects in contact. Oxford: Blackwell, 1986.

\begin{abstract}
This research had the objective of describing the segmental characteristics of the TV broadcast in two cities (Recife and Maceió), in spontaneous and professional emission. This study was carried out in the Central Globo of Journalism and Sport Station in Recife, and the afiliated Rede Globo in Maceió. In order to evaluate the spontaneous emission, it was used conversations about the personal experiences. To the professional emission, it was asked to the reporters to read a standard text, simulating the narrating style of the TV broadcast. The reporters and TV presenters from Recife and Maceió modified their pronunciation of origin in the professional speech, but in the spontaneous emission there was a "relaxation" in keeping the broadcasting standard.
\end{abstract}

Keywords: Linguistic variation. Accent. TV broadcast 